\title{
The Impact of Emotion of Shu Lin's Translation of David Copperfield
}

\author{
Chenyu Shen ${ }^{1}$ \\ ${ }^{1}$ School of Foreign Studies, Hefei University of Technology, XuanCheng, Anhui 242000, China \\ *Corresponding author. Email: Chuguotougao@163.com
}

\begin{abstract}
Shu Lin allows his emotions to affect his translation of English literature in order to communicate his thoughts and ideas to awaken the young and to improve social morals. Owing to a series of emotions that arise from his value, social customs, and ideas concerning education, there is a dispute about his unfaithfulness to the original text in his translation of Charles Dickens' David Copperfield. This includes deviation, strengthening or weakening of certain emotions, and changes in narrative perspective. This paper examines these three types of unfaithful translation, discussing the impact of emotion in his translation of this novel. In so doing, it not only uncovers the causes of Lin's emotions during his translation but also illuminates the distinct emotional style of late Qing society.
\end{abstract}

Keywords: Shu Lin; Charles Dickens; David Copperfield; translation; emotion

\section{INTRODUCTION}

Shu Lin (1852-1924), known for translating and introducing Western literature to Chinese readers, was the first Chinese translator to advocate for affective translation. Lin translated novels carrying subjective emotions with specific purposes not only for displaying the reader community western culture and society, but also for communicating his own value and spirit, hoping to arouse the reader's patriotic consciousness[1]. In this sense, the translated work carries Lin's social ideas and ambition, which function as the source of the strength readers could rely on. Lin despises human faults and social ills while reserving his sympathy for the weak and the virtuous. Translating English literature with a clear aim to enlighten the reading public so as to improve social ethos, Lin allows these emotions to bear upon his translation to that effect. As a result, his translated works display significant inconformities to the original English texts, in plots and characterization. For instance, when he translates David Copperfield, he translates "you must try to look at it from a new point of view" [2] into " you must be ambitious"[3]. ${ }^{1}$ Considering the young as the hope of rejuvenating the nation in the late Qing dynasty, Lin deliberately adds in his translation a high expectation for David. In so doing, he can elicit ambitions in his young readers.

Some translators, such as Jianzhong $\mathrm{Xu}$ and Lihua Yang, mark Lin's "unfaithful" translation unique and accessible to the reading public [4] [5]. In contrast, some critics insist on absolute loyalty to the original text. For instance, Xun Lu, a pioneering modern literary translator, values faithfulness over smoothness. In his own words, he would "rather be faithful than smooth" [6]. In the same understanding, Fan
Cunzhong also states that "translation denotes faithful representation of what is written or said in a different language" [7].

It is not the aim of this paper to take a side in this ongoing debate. Instead, it seeks to examine the effect of emotion on Lin's translation, given the scant research on this topic and its importance in understanding his translation strategies. Towards this aim, I will draw upon the theory of emotion, in particular William M. Reddy's theory of emotional styles, to analyze the emotional aspects of his translation of David Copperfield.

By emotional styles, Reddy emphasizes the coherence between emotion and its time and place. In his own words, "Emotional styles come and go, develop or decay, according to whether they work for communities" [8]. Whether a type of emotional style thrives or prevails in a specific society of a specific era depends on whether it speaks to the values, customs and ethics of the corresponding community. Reddy also mentions that for an emotional style to "work," it shall be able to "call forth" [8]. That is to say, the emotional expression characterized by the emotional style matching the community will appeal to the community members. In light of Reddy's ideas, I will call attention to the distinct emotional styles of Victorian society and that of late Qing society, significantly due to their different social reality, value systems, and culture in a broad sense. More specifically, Lin's sentiment shaped by his values, beliefs, and the moods of late Qing society, have placed significant influence on his translation.

In the following parts, I will first discuss the influence of his status as a scholar-official in feudal China, arguing that his values drive him to delete and modify some contents. Then I will list his purposefully weakened and strengthened emotions in some scenes. These inconformities result from

1 All Lin's translations are translated into English by the present author unless otherwise explained. 
his life experience, habits, and moral values. Finally, I call attention to his understanding of Chinese novels and his readership in the late Qing dynasty, due to which, he deploys different narrative perspectives of help in endearing his translation to the readers of the day. Throughout discussing Lin's translation of David Copperfield as it was affected by his emotion, this paper yields a new light in understanding his distinct translation strategies and more broadly, the relationship between emotion and translation, calling for critical attention to the long-neglected role of emotion in translation.

\section{THE ANALYSIS ON THE UNFAITHFULNESS IN LIN'S TRANSLATION OF DAVID COPPERFIELD}

\subsection{Translation deviations and Lin's educational purpose}

Lin was a man of patriotism, with a proposition that the youth should be inspired to take the responsibility of national revival [9]. As a leading scholar-official at that time, he paid particular attention to education and cultivation targeted at the young generation, sponsoring a great number of students for further study abroad. Besides, he was influenced by Confucianism which formulated various requirements and rules in the hope of educating people to be responsible and virtuous citizens for society and nation. Confucianism affected his life experience, informing his value as well, with many of his educational idea reverberating with the Confucian classics The Analects of Confucius. This work advances the view insisting that "An educated gentlemen cannot but be resolute and broadminded, for he has taken up a heavy responsibility and a long course" [10]. With Lin being a cultural product of Confucianism, unsurprisingly, he advised the young to harbor a sense of social responsibility and to be prepared for a life-long pursuit of achievement and success. Correspondingly, he loathed indulgence in pleasure and loss of aspiration. Affected by these sentiments, Lin alters some of David's views of life, adding materials somewhere and deleting some original ideas of Dickens at some other times. A proper example can be found in Lin's dealing with the words of David's aunt, who discusses with Mr. Wickfield about the motives of education.

FORM1:

\begin{tabular}{|l|l|}
\hline The original text & Lin's translation \\
\hline "Always fishing for & "Children study merely for \\
motives, when they're on & learning skills and \\
the surface! Why, to make & becoming someone useful. \\
the child happy and & There isn't any other \\
useful." (Dickens 238) & motive." (Lin 128) \\
\hline
\end{tabular}

We can see quite a difference between the original text and Lin's translation. Through the character of David's aunt,
Dickens acknowledges the entertaining function of education apart from its practical role in transforming a man in service of society. The aunt hopes that education will enable David to realize his dream and at the same time, to stay cheerful and happy. However, Lin deliberately erases the entertaining dimension of education, with a sole emphasis on the usefulness of knowledge. It is noteworthy that Lin even opposes enquiries about other motives of education except for its usefulness, which suggests his disgust at the pursuit of pleasure in education. The influence of Confucian belief in hard work and labour is evident here. According to Confucianism, "a man has to hone his will, strain his bones and muscles, make his body suffered, and experience poverty before he is trusted with a great task" [11]. Therefore, we can arrive at the argument that Lin alters the purposes of education applauded by Dickens because of his firm belief in the transformative power of struggle and hardship in education. Here is another example:

FORM2:

\begin{tabular}{|l|l|}
\hline The original text & Lin's translation \\
\hline $\begin{array}{l}\text { "I suppose the opening } \\
\text { prospect confused me. I } \\
\text { know that my juvenile }\end{array}$ & $\begin{array}{l}\text { Everything seems fine } \\
\text { regarding my future, but I } \\
\text { get confused about so } \\
\text { experiences went for little } \\
\text { many choices. It seems } \\
\text { or nothing then; and that life } \\
\text { that my lifelong career is } \\
\text { was more like a great fairy } \\
\text { story, which I was just } \\
\text { about to begin to read, than } \\
\text { anything else." (Dickens } \\
\text { 154). }\end{array}$ \\
\hline
\end{tabular}

David considers his unknown future experiences as "a great fairy tale." However, Lin does not translate this layer of David's opinion but emphasizes his life prospect instead, suggesting that it would be a tremendous and ambitious career. What Regenia Gagnier says about the way Chinese scholars use western literature helps to unpack the causes of Lin's intriguing translation here. According to Gagnier, affected by Lu Xun's philosophy of pragmatism, Chinese reformers borrowed what they needed but discarded what they considered useless in reforming the old China [12]. In the same vein, Lin deletes some contents deliberately, significantly because the emotional community of which Lin was a member differed from the one in which Dickens formed his value, belief, and emotional attitudes towards the problem-fraught society.

In David Copperfield, most characters aspire for nothing more than a happy life, with none of them aspiring for a higher purpose in term of serving the nation, society, and humanity. This phenomenon has something to do with the context Dickens was in. As Britain rose to become the leading empire in the Victorian period, and the first industrial revolution endowed people with more leisure time as the unprecedentedly advanced machines shortened laboring time and increasing the unemployment rate. Despite the rapid growth of the economy, there still was a large gap between the upper-level and bottom-level people. According to Tamara Ketabgian, Victorian people had long 
been famed for their organic sympathies, their stalwart humanism, their tragic vision of industrial alienation, and their corresponding antipathy toward the machine [13]. In addition to their complex emotions towards machines, many other emotions originated from the impoverished people who were unable to afford to chase their ambitions but got stuck in a trivial life. Under such a complex and mixed social circumstance, Victorian people advocated for literature, art, and moral cultivation, focusing on individuals, personal pleasure, and spiritual comforts [14]. However, in the late Qing dynasty, China was defeated in the Sino-Japanese War in 1895, as a result of which, the government signed the treaty of Shimonoseki. Saddened by the lost territories and indemnities, Lin and a large group of politicians proposed that China had to revolutionize the education of the young responsible so as to protect the nation and to restore its power and dignity in the face of the threatening western powers [9]. One of Lin's friends, Han Wei, also states in the preface of Lin's poetry anthology that the young should be educated to meet the enemy of their country [15]. The Qing society, different from the society in which Dickens wrote the novel, was dominated by an urge to educate the youth for a higher purpose than mere personal happiness. In consequence, the novelist and the translator emphasize different aspects of David's future. Through translating "a great fairy story" into "the life career," Lin expresses his idea of education, which will spark empathy among his fellow countrymen.

\subsection{The strengthening and weakening of certain emotions}

Apart from conspicuous deletion of original texts, Lin tends to alter Dickens' descriptions of actions and conversations to modify the intensity of emotions connected to these descriptions, owing to his emotional fluctuations. His deliberate strengthening or weakening of certain emotions connects closely with his distinct life experience and the historical context, which were different from Dickens'.

Dickens spent his childhood under the poverty and massive pressure of debt, which bore his masterpiece David Copperfield. The characters in this novel manifest love, optimism, cheerfulness, romance and other strong emotions. For instance, David holds high hope for future life and expresses innocent and immature affection for his childhood playmate Emily. Moreover, Dickens created this novel with biting critical realism, combining what he saw and understood to draw a detailed picture of nineteenth-century British society. During this process, he expressed sympathy for the socially disadvantaged but threw anger at the bad and the evil.

Lin, however, is not comfortable with some emotions expressed in the original text, for instance, frank and bold expressions of affection and love. In Chapter 10, Dickens details the complex emotional responses of Peggotty when her marriage with Mr. Barkis is announced to the public. Peggotty surely felt happy with marrying the man, but she "was resolved that it should be quietly done," hoping not to have any "witnesses of the ceremony." As a result, she was:

FORM3:

\begin{tabular}{|l|l|}
\hline The original text & Lin's translation \\
\hline $\begin{array}{l}\text { a little confused when Mr. } \\
\text { Barkis made this abrupt } \\
\text { announcement of their }\end{array}$ & $\begin{array}{l}\text { Everything seems fine } \\
\text { regarding my future, but } \\
\text { I get confused about so } \\
\text { union, and could not hug } \\
\text { many choices. It seems } \\
\text { me enough in token of her } \\
\text { that my lifelong career is } \\
\text { unimpaired affection; but } \\
\text { she soon became herself } \\
\text { again, and said she was } \\
\text { very glad it was over. } \\
\text { (Dickens, 159) }\end{array}$ \\
\hline
\end{tabular}

Lin translates Peggoty's confusion about the sudden public announcement of their marriage to bashfulness and prudency. Accordingly, he ignores her enthusiastic hugs for David for these tokens of "unimpaired affection" evidently contradicts what he translates as her shyness. This is because the traditional culture of Qing dynasty had its distinct emotional style in term of affections and its ways of expressing such feelings. In the feudal society, affections between the two sexes were considered as private and domestic. Therefore, people were uncomfortable with public expressions of affections, which was considered as harmful for morals. For the female sex, they tended to be conservative about their marriage because things related to sex was inappropriate for public revelation and discussion. At that time, many traditional poems write about this cultural custom. For instance, in "Last Midnight," Zhuang Wei draws an image of a girl who is excited with mixed emotions of shyness gladness when meeting the man she loves. Similarly, the poet Jianwu Shi also depicts a girl who lows her head to avoid eye contact with other people for feeling shy when learning the manner of marriage. These poems all reveals that females' public bashfulness towards matters related to love and marriage was a traditional social custom. Consequently, Lin translates Peggoty's emotions in a way to match the behavioral pattern regarding affections in his own culture. In this way, the reading public, particularly female readers, can better empathize with Peggoty.

In another occasion, Lin strengthens David's anger when Miss. Murdstone criticizes his aunt disrespectfully.

FORM4:

\begin{tabular}{|c|l|}
\hline The original text & Lin's translation \\
\hline $\begin{array}{c}\text { I felt very fiery on my } \\
\text { aunt's account; but I said it }\end{array}$ & $\begin{array}{l}\text { So irritated was I by her } \\
\text { censure on my aunt that I } \\
\text { would certainly be better, if } \\
\text { said angrily: “if you don't } \\
\text { Miss. Murdstone pleased, } \\
\text { mention her, I think you're } \\
\text { not to mention her. I could } \\
\text { in the right place. I detest } \\
\text { not hear her disrespectfully } \\
\text { mentioned, I added, } \\
\text { those who mention her } \\
\text { without expressing my } \\
\text { opinion in a decided tone. } \\
\text { (Dickens, 421) }\end{array}$ \\
\hline
\end{tabular}


In the original context, although David feels unhappy with Miss Murdstone's unfriendly comments on his aunt, he manages to show some respect for Miss. Murdstone. Despite his ardent hope that Miss Murdstone will not say anything disrespectful about his loved ones, he does not firmly state this view. However, in Lin's translation, David displays a firmer stance on this matter, stating outright with anger: "I detest those who mention her disrespectfully." In this way, Lin strengthens David's anger.

This is because Miss Murdstone's disrespect for his aunt goes against the traditional value in late Qing, which advocated strict respect for the elders. For example, Mencius, a philosopher in ancient China, said: " As long as everyone respects their parents and the elders, the society will be harmonious" [11]. Affected by such Confucian notions, Lin could have been irritated by Miss Murdstone's insult of David's aunt. The intensity of his anger at this behavior manifests in his use of an exclamation mark at the end of the sentence. Accordingly, he exaggerates David's discomfort with Miss Murdstone. With his anger more visible to his readers, Lin will be able to educate his countrymen and to cultivate virtues.

As discussed above, the society of a particular culture has its distinct emotional style. When Lin weakens or strengthens certain emotions towards certain behaviors, he is exciting an impact in the emotional community of the late Qing Dynasty. According to Lefevere, who puts forward the concept of manipulation in translating, translators rewrite in some degree so that their translation will conform to the dominated ideology and forms, which stands for an important way to promote the development of literature and more importantly, the ideas embedded in the text [16].

\subsection{The switching of narrative perspectives}

Had been living his whole life as a native Chinese, Lin possessed adequate knowledge of Chinese readers. As an erudite and dedicated reader, he read at least two- thousand volumes of ancient Chinese works [17]. As a result, he knew how to alter the text in a way to speak and appeal to his readers' emotions, thereby communicating to them the values, ideas, and opinions endorsed by him. This contributes to the popularity of his translated works.

In order to avoid possible confusions and to conform to the aesthetics of Chinese novels in his times, he translates some scenes by using narrative perspectives different from the original text. This leads to switches between indirect speech and direct speech in translating this novel. For instance, in Chapter 18, when describing the interaction between David and the butcher, Lin changes the description of the butcher's provocation into a direct speech, painting a more vivid picture for his readers.
FORM5:

\begin{tabular}{|l|l|}
\hline The original text & Lin's translation \\
$\begin{array}{l}\text { He waylays the smaller } \\
\text { unprotected punch their }\end{array}$ & $\begin{array}{l}\text { Sometimes, he waylays the } \\
\text { smaller boys by the sides } \\
\text { calls challenges after me in } \\
\text { of the roads to grasp their } \\
\text { hair who do not wear a hat. } \\
\text { the open streets. For these } \\
\text { sufficient reasons I resolve } \\
\text { to fight the butcher. } \\
\text { (Dickens 288) }\end{array}$ \\
$\begin{array}{l}\text { in the street, he calls out to } \\
\text { me: "Mr. Copperfield, do } \\
\text { you dare to fight me? He } \\
\text { has been challenging me } \\
\text { quite frequently. For this } \\
\text { reason, I can no longer put } \\
\text { up with this and resolve to } \\
\text { fight the butcher. (Lin } \\
\text { 155) }\end{array}$ \\
\hline
\end{tabular}

In the translation, Lin uses direct speech to represent butcher's calls for challenges, imagining his direct provoking of conflict: "Mr. Copperfield, do you dare to fight me?" The direct speech helps to represent the intensity of conflict between the two characters. Moreover, it is easier for his readers to imagine David's confrontation with the defiant butcher, whose provocation grows increasingly intolerable. According to what Shen Dan writes in the Development and Interrelation between Narratology and Stylistics of Fiction (2001), traditional Chinese fictions originated from storytelling, because story-tellers preferred using the characters' original expressions, and later novelists followed this narrative perspective [18]. Affected by this narrative tradition, he translates this scene deliberately in a way to bring his readers closer to an emotionally charged moment.

Another example can be found in Chapter 53. When David's profoundly quiet and attentive aunt seizes Heep's collar with both hands, David has to put himself between them and calm his aunt her down. Again, Lin translates this scene using direct speech, instead of following Dickens' use of indirect speech.

\section{FORM6:}

\begin{tabular}{|l|l|}
\hline The original text & Lin's translation \\
\hline I hastened to put myself & I did my utmost to stop my \\
between them, and to & aunt's pulling at Heep's \\
assure her that we would & collar: "I would make the \\
all take care that he should & earnest effort to get all his \\
make the utmost & ill-gotten wealth back to \\
restitution of everything & you." (Lin 428) \\
he had wrongly got. & \\
(Dickens 817) & \\
\hline
\end{tabular}

Compared with Dickens's description of the interaction between David and his aunt, Lin's translation allows his 
readers to hear what David says to his aunt exactly. In this way, they can better perceive David's kindness to and gratitude for his aunt who has paid for his living and education. Besides, Lin changes "we would all take care" into "I would make the earnest effort to," deliberately stressing David's determines to act for his aunt. This subtle change also caters to the traditional Chinese value mentioned above that the young should respect and take care of the elders. By switching narrative perspectives, Lin better speaks to the tradition and value of Qing dynasty, thereby enabling his readers to empathize with the characters imperceptibly.

\section{CONCLUSION}

To conclude, Lin's emotion influences his translation. On the one hand, affected by Confucianism, he believes that only by suffering from hardship and diligent study can one acquire the capability of serving the country. Thinking as such, he abhors David's pursuit of pleasure, and accordingly, in his translation, David is educated to go after an ambitious career. On the other hand, with different life experience and living in a different historical context, Lin strengthens or weakens some emotional fluctuations in the original texts to make sure that they conform to the dominant ideology and value of the reader community. Furthermore, Lin alters the narrative perspectives in the purpose of emphasizing certain qualities of characters. In this way, he hopes to appeal to Chinese reader's emotions so as to imperceptibly convey the virtues and qualities he admires.

However, it has to be admitted that there exists another factor shaping Lin's understanding and emotions. Due to his limited knowledge of foreign languages, he relied on help from interpreters. To ascertain the role of the interpreter in his emotional translation, future study is awaited.

\section{REFERENCES}

[1] Guan, Zhi. “A Brief Analysis of Lin Shu's Translation of Emotional Literature." Culture·Cultural Industry Forum 2014, 60 .

[2] Dickens, Charles. David Copperfield. E-book, GlobalGrey, 2018, 295.

[3] Lin, Shu and Yi Wei. David Copperfield (Kuai Rou Yu Sheng Shu). Beijing: The Commercial Press, 1981, 160.

[4] Xu, Jianzhong. "Re-Evaluation of Lin Shu (the Chinese Translator): A Systemic Approach to Literary Translation." Translation Today Oct 2005, 150.

[5] Yang, Lihua. "Translator's Subjectivity in Lin Shu's Translation." Cross-Cultural Communication, April 2013, 27.
[6] Lu, Xun. "The Reply to Qiubai Qu from Xun Lu." The Analects of Translation, edited by Luo, Xinzhang. Beijing: The Commercial Press, 1984, 275.

[7] Fan, Cunzhong. A Collection of Essays on Translation Theory and Translation Techniques. Beijing: China Translation and Publication Corporation, 1983, 80.

[8] Reddy, William M. The Navigation of Feeling: A Framework for the History of Emotions. Cambridge: Cambridge University Press, 2011, 85, 85.

[9] Hu, Quanzhang. "Constitutional Reform in the World of Poem: The Historical Meaning of Shu Lin's Collection of New Yuefu in Mingzhong." Journal of Huaiyin Teachers College Mar 2016, 370, 371.

[10] Confucius. The Analects of Confucius. Beijing: Zhonghua Book Company, 2007, 109.

[11] Mencius. Mengzi. Beijing: Zhonghua Book Company, 2006, 285, 285.

[12] Gagnier, Regenia. "The Global Circulation of Charles Dickens's novels.” Literature Compass Oct 2013, 88.

[13] Ketabgian, Tamara Siroone. The Lives of Machines: the Industrial Imaginary in Victorian Literature and Culture. Michigan: The University of Michigan Press, 2010, 1.

[14] Xu, Chendi. "Brief Analysis on British Society in the Nineteenth Centuries Reflected by David Copperfield." Masterpieces Review 2019, 165.

[15] Li, Linzhou. "Analysis on Shu Lin's preschool education view from Collection of New Yuefu in Mingzhong." Education Criticism 1988, 46.

[16] Lefevere, Andre. Translation, Rewriting and the Manipulation of Literary Fame. London: Routledge, 1992, 14.

[17] Li, Jian. "A talent of translation who does not understand foreign Language.” Yunnan Archives May 2014, 17.

[18] Shen, Dan. Development and Interrelation between Narratology and Stylistics of Fiction. Beijing: Peking University Press, 2001, 17. 